\section{ASSOCIATION OF THE LUPUS LOW DISEASE ACTIVITY STATE (LLDAS) WITH HEALTH RELATED QUALITY OF LIFE}

${ }^{1} V$ Golder*, ${ }^{1} \mathrm{R}$ Kandane-rathnayake, ${ }^{1} \mathrm{~A}$ Hoi, ${ }^{2} \mathrm{M}$ Huq, ${ }^{3} \mathrm{~W}$ Louthrenoo, ${ }^{4} \mathrm{Y}$ An, ${ }^{4} \mathrm{ZG} \mathrm{Li}$, ${ }^{4} \mathrm{SF}$ Luo, ${ }^{56}, \mathrm{~S}$ Sockalingam, ${ }^{7} \mathrm{CS}$ Lau, ${ }^{7,8} \mathrm{MY}$ Mok, ${ }^{78},{ }^{8} \mathrm{~A}$ Lateef, ${ }^{9} \mathrm{~S}$ Navarra, YJ Wu ${ }^{5},{ }^{10} \mathrm{~L}$ Hamijoyo, ${ }^{11} \mathrm{M}$ Chan, ${ }^{12} \mathrm{~S} \mathrm{O}^{\prime} \mathrm{Neill},{ }^{13} \mathrm{~F}$ Goldblatt, ${ }^{2} \mathrm{M}$ Nikpour, ${ }^{1} \mathrm{E}$ Morand. ${ }^{1}$ School of Clinical Sciences at Monash Health, Rheumatology, Clayton, Australia; ${ }^{2}$ Melbourne University, Rheumatology, Fitzroy, Australia; ${ }^{3}$ Chiang Mai University Hospital, Rheumatology, Chiang Mai, Thailand; ${ }^{4}$ People's Hospital- Peking University Health Sciences Centre, Rheumatology, Beijing, China; ${ }^{5}$ Chang Gung Memorial Hospital, Rheumatology, Guishan Township, Taiwan R.O.C; ${ }^{6}$ University of Malaya, Rheumatology, Kuala Lumpur, Malaysia; ${ }^{7}$ Hong Kong University, Rheumatology, Hong Kong, Hong Kong S.A.R; ${ }^{8}$ National University Hospital, Rheumatology, Singapore, Singapore; ${ }^{9}$ University of Santo Tomas Hospital, Rheumatology, Manila, Philippines; ${ }^{10}$ University of Padjadjaran, Rheumatology, Bandung, Indonesia; ${ }^{11}$ Tan Tock Seng Hospital, Rheumatology, Singapore, Singapore; ${ }^{12}$ South Western Sydney Clinical School, Rheumatology, Liverpool, Australia; ${ }^{13}$ Royal Adelaide Hospital, Rheumatology, Adelaide, Australia

\subsection{6/lupus-2017-000215.33}

Background and Aims Systemic lupus erythematosus (SLE) is associated with significant impairment of health-related quality of life (HR-QoL). The Lupus Low Disease Activity State (LLDAS) definition has not been previously evaluated for association with patient reported outcomes. The objective of this study was to determine whether LLDAS was associated with better HR-QoL, and examine predictors of HR-QoL, in a large multiethnic, multinational cohort of SLE patients.

Methods HR-QoL was measured using the Medical Outcomes Study 36-item Short Form Health Survey (SF-36v2) in a prospective study of 1422 patients. Disease status was measured using SLE disease activity index (SLEDAI-2K), physician global assessment (PGA) and LLDAS.

Results Significant differences in SF-36 domain scores were found between patients stratified by ethnic group, education level, damage score, and with the presence of active musculoskeletal or cutaneous manifestations. In multiple linear regression analysis, Asian ethnicity $(\mathrm{p}<0.001)$, a higher level of education $(\mathrm{p}<0.001)$, younger age $(\mathrm{p}<0.001)$ and shorter disease duration $(p<0.01)$ remained significantly associated with better physical component scores (PCS). Musculoskeletal disease activity $(\mathrm{p}<0.001)$ was negatively associated with PCS, and cutaneous activity $(\mathrm{p}=0.04)$ was negatively associated with mental component scores (MCS). Patients in LLDAS had better PCS $(p<0.001)$ and MCS $(p<0.001)$ scores and significantly better scores in multiple individual SF-36 domain scores. Disease damage was associated with worse PCS $(\mathrm{p}<0.001)$, but not MCS scores.

Conclusions Ethnicity, education, disease damage, and specific organ involvement impacts on HR-QoL in SLE. Attainment of LLDAS is associated with better HR-QoL.

\section{COMPARISON OF REMISSION AND LUPUS LOW ACTIVITY STATE AS PREDICTORS OF ORGAN DAMAGE}

${ }^{1} \mathrm{M}$ Petri ${ }^{*},{ }^{2} \mathrm{~L}$ Magder. ${ }^{1} J o h n s$ Hopkins University, Baltimore, USA; ${ }^{2}$ University of Maryland, Biostatistics, Baltimore, USA
Background and Aims Outcome measures that combine control of SLE activity and prednisone reduction are clinically relevant. A clinical goal in SLE is to reduce risk of long-term organ damage. We assessed whether two recently proposed disease activity outcomes were predictive of future damage.

Methods For each month of follow-up, we determined whether the patient was in Clinical Remission (as defined by the DORIS work group) or low lupus disease activity state (LLDAS) (as defined by Franklyn et al.). Clinical Remission was defined as a PGA $<0.5$, clinical SLEDAI $=0$ and no prednisone or immunosuppressants. Clinical Remission on Treatment allowed for prednisone $<=5 \mathrm{mg} /$ day and immunosuppressant use. LLDAS was defined as a SLE$\mathrm{DAI}<=4$, PGA $<=1.0$, no major organ activity, and no new activity. LLDAS on treatment allowed for prednisone use $<=7.5 \mathrm{mg} / \mathrm{d}$ and immunosuppressants. Damage was defined using the SLICC/ACR index.

Results There were 81118 person-months observed among 2026 patients $(92 \%$ female, 53\% Caucasian, 39\% AfricanAmerican). Table 1 shows the rates of damage, per person month, in subgroups defined by Remission or LLDAS.

Damage rates were relatively low when LLDA was achieved at least $50 \%$ of the time. These rates were similar to those experienced by patients who met a more stringent treatment restriction with Remission on Treatment at least 50\% of the time.

Conclusions The equivalence of LLDAS and DORIS remission on treatment is welcome news, as LLDAS on treatment $>50 \%$ of the time is an easier goal to achieve (3 times more personmonths observed in our cohort) and more realistic as a clinical trial outcome.

\begin{tabular}{|c|c|c|c|c|c|}
\hline $\begin{array}{l}\text { Percentage of Prior } \\
\text { Months in: }\end{array}$ & $\begin{array}{l}\text { Number of } \\
\text { person- } \\
\text { months } \\
\text { observed }\end{array}$ & $\begin{array}{l}\text { Number of } \\
\text { months with } \\
\text { an increase } \\
\text { in } \\
\text { SLICC/ACR } \\
\text { damage } \\
\end{array}$ & $\begin{array}{l}\text { Rate of } \\
\text { damage } \\
\text { per } 100 \\
\text { person } \\
\text { months }\end{array}$ & Rate Ratios & P-values \\
\hline $\begin{array}{l}\text { Clinical Remission } \\
\text { None } \\
\text { Not none, but }<25 \% \\
25 \% \text { to } 50 \% \\
50 \% \text { to } 75 \% \\
75 \%+ \\
\end{array}$ & \begin{tabular}{|l}
35,772 \\
14,358 \\
6573 \\
3845 \\
1,641 \\
\end{tabular} & \begin{tabular}{|l}
406 \\
102 \\
50 \\
27 \\
10 \\
\end{tabular} & $\begin{array}{l}1.13 \\
0.71 \\
0.76 \\
0.70 \\
0.61 \\
\end{array}$ & $\begin{array}{l}1.0 \text { (Ref) } \\
0.60(0.48,0.75) \\
0.66(0.46,0.94) \\
0.63(0.42,0.97) \\
0.58(0.30,1.15)\end{array}$ & \begin{tabular}{|l|}
$<0.0001$ \\
0.023 \\
0.035 \\
0.12 \\
\end{tabular} \\
\hline $\begin{array}{l}\text { Clinical Remission on } \\
\text { Treatment } \\
\text { None } \\
\text { Not none, but }<25 \% \\
25 \% \text { to } 50 \% \\
50 \% \text { to } 75 \% \\
75 \%+ \\
\end{array}$ & \begin{tabular}{|l|}
16,491 \\
20,169 \\
14,344 \\
8396 \\
2,789 \\
\end{tabular} & \begin{tabular}{|l|}
250 \\
170 \\
103 \\
54 \\
18 \\
\end{tabular} & $\begin{array}{l}1.52 \\
0.84 \\
0.72 \\
0.64 \\
0.65\end{array}$ & $\begin{array}{l}1.0 \text { (Ref) } \\
0.54(0.44,0.67) \\
0.46(0.36,0.60) \\
0.43(0.30,0.60) \\
0.45(0.27,0.75)\end{array}$ & $\begin{array}{l}<0.0001 \\
<0.0001 \\
<0.0001 \\
0.0019\end{array}$ \\
\hline \begin{tabular}{|l|} 
LLDAS \\
None \\
Not none, but $<25 \%$ \\
$25 \%$ to $50 \%$ \\
$50 \%$ to $75 \%$ \\
$75 \%+$ \\
\end{tabular} & \begin{tabular}{|l}
30,366 \\
10,880 \\
5012 \\
8494 \\
7,527 \\
\end{tabular} & \begin{tabular}{|l|}
343 \\
106 \\
40 \\
60 \\
46 \\
\end{tabular} & $\begin{array}{l}1.13 \\
0.97 \\
0.80 \\
0.71 \\
0.61 \\
\end{array}$ & $\begin{array}{l}1.0 \text { (Ref) } \\
0.86(0.69,1.07) \\
0.70(0.51,0.98) \\
0.63(0.48,0.83) \\
0.54(0.40,0.73)\end{array}$ & \begin{tabular}{|l}
0.18 \\
0.037 \\
\\
$<0.0001$ \\
\end{tabular} \\
\hline $\begin{array}{l}\text { LLDAS on Treatment } \\
\text { None } \\
\text { Not none, but }<25 \% \\
25 \% \text { to } 50 \% \\
50 \% \text { to } 75 \% \\
75 \%+ \\
\end{array}$ & $\begin{array}{l}7,656 \\
10,555 \\
12,686 \\
18,151 \\
13,141\end{array}$ & $\begin{array}{l}117 \\
134 \\
129 \\
133 \\
82\end{array}$ & $\begin{array}{l}1.53 \\
1.27 \\
1.02 \\
0.73 \\
0.62\end{array}$ & $\begin{array}{l}1.0 \text { (Ref) } \\
0.83(0.65,1.06) \\
0.66(0.51,0.85) \\
0.48(0.37,0.61) \\
0.40(0.30,0.54)\end{array}$ & $\begin{array}{l}0.14 \\
0.0013 \\
0.0010 \\
<0.0001\end{array}$ \\
\hline
\end{tabular}

